\title{
New iterative schemes for a finite family of nonself uniformly quasi-Lipschitzian mappings in Banach spaces
}

Chao Wang ${ }^{1,4}$, Jin $\mathrm{Li}^{2^{*}}$ and Liang-gen $\mathrm{Hu}^{3}$

\author{
* Correspondence: jinli@mail.zjgsu. \\ edu.cn \\ ${ }^{2}$ School of Computer and \\ Information Engineering, Zhejiang \\ Gongshang University, Hangzhou \\ 310018, People's Republic of China \\ Full list of author information is \\ available at the end of the article
}

\begin{abstract}
In this article, we introduce the concept of nonself uniformly quasi-Lipschitzian mapping and consider a new iterative scheme with errors to converge to a common fixed point for a finite family of nonself uniformly quasi-Lipschitzian mappings in Banach spaces. The results of this article improve and extend many known results.

Keywords: nonself uniformly quasi-Lipschitzian mapping, new iterative scheme with errors, common fixed point, Banach spaces
\end{abstract}

\section{Introduction and preliminaries}

Throughout the article, we assume that $X$ is a real Banach space, $C$ is a nonempty subset of $X$, and $\operatorname{Fix}(T)$ is the set of fixed points of mapping $T$, i.e., $\operatorname{Fix}(T)=\{x \in C: T x=x\}$.

Definition 1.1. Let $T: C \rightarrow C$ be a mapping.

(1) $T$ is said to be asymptotically nonexpansive if there exists a sequence $\left\{k_{n}\right\} \subset[1, \infty)$ with $\lim _{n \rightarrow \infty} k_{n}=1$ such that

$$
\left\|T^{n} x-T^{n} y\right\| \leq k_{n}\|x-y\|
$$

for all $x, y \in C$ and $n \geq 1$.

(2) $T$ is said to be uniformly Lipschitzian if there exists a constant $L>0$ such that

$$
\left\|T^{n} x-T^{n} y\right\| \leq L\|x-y\|
$$

for all $x, y \in C$ and $n \geq 1$.

(3) $T$ is called asymptotically quasi-nonexpansive if there exists a sequence $\left\{k_{n}\right\} \subset$

$[1, \infty)$ with $\lim _{n \rightarrow \infty} k_{n}=1_{\text {such that }}$

$$
\left\|T^{n} x-p\right\| \leq k_{n}|| x-p \|
$$

for all $x \in C, p \in \operatorname{Fix}(T)$ and $n \geq 1$.

Remark 1.1. (i) The concept of asymptotically nonexpansive mapping was initially introduced by Geobel and Kirk [1]. Meanwhile, they proved that if $C$ is a nonempty

(c) 2012 Wang et al; licensee Springer. This is an Open Access article distributed under the terms of the Creative Commons Attribution License (http://creativecommons.org/licenses/by/2.0), which permits unrestricted use, distribution, and reproduction in any medium, provided the original work is properly cited. 
closed, convex, and bounded subset of a uniformly convex Banach space, then every asymptotically nonexpansive mapping has a fixed point.

(ii) It is easy to see that if $T$ is an asymptotically nonexpansive mapping, then $T$ is a uniformly Lipschitzian mapping (taking $L=\sup _{n \geq 1} k_{n}$ ), and if $\operatorname{Fix}(T) \neq \varnothing$, then every asymptotically nonexpansive mapping $T$ is an asymptotically quasi-nonexpansive mapping.

Definition 1.2. Let $X$ be a real Banach space and $C$ be a nonempty subset of $X$.

(1) A mapping $P: X \rightarrow C$ is said to be retraction if $P^{2}=P$.

(2) If there exists a nonexpansive retraction $P: X \rightarrow C$ such that $P x=x$ for all $x \in$

$C$, then the set $C$ is said to be nonexpansive retract of $X$.

Next, we introduce some concepts for nonself mappings.

Definition 1.3. Let $X$ be a real Banach space, $C$ be a nonempty subset of $X$, and $P$ : $X \rightarrow C$ the nonexpansive retraction of $X$ onto $C$. Let $T: C \rightarrow X$ be a nonself mapping.

(1) $T$ is said to be nonself asymptotically nonexpansive if there exists a sequence $\left\{k_{n}\right\}$

$\subset[1, \infty)$ with $\lim _{n \rightarrow \infty} k_{n}=1_{\text {such }}$ that

$$
\left\|T(P T)^{n-1} x-T(P T)^{n-1} y\right\| \leq k_{n}\|x-y\|
$$

for all $x, y \in C$ and $n \geq 1$.

(2) $T$ is said to be nonself uniformly Lipschitzian if there exists a constant $L>0$ such that

$$
\left\|T(P T)^{n-1} x-T(P T)^{n-1} y\right\| \leq L|| x-y||
$$

for all $x, y \in C$ and $n \geq 1$.

(3) $T$ is said to be nonself asymptotically quasi-nonexpansive if there exists a sequence $\left\{k_{n}\right\} \subset[1, \infty)$ with $\lim _{n \rightarrow \infty} k_{n}=1$ such that

$$
\left\|T(P T)^{n-1} x-p\right\| \leq k_{n}\|x-p\|
$$

for all $x \in C, p \in \operatorname{Fix}(T)$ and $n \geq 1$.

(4) $T$ is said to be nonself uniformly quasi-Lipschitzian if there exists a constant $L>$ 0 such that

$$
\left\|T(P T)^{n-1} x-p\right\| \leq L\|x-p\|
$$

for all $x \in C, p \in \operatorname{Fix}(T)$ and $n \geq 1$.

Remark 1.2. (i) The concept of nonself asymptotically nonexpansive mapping was introduced by Chidume et al. [2] which is a generalization of asymptotically nonexpansive self-mapping. 
(ii) If $T$ is a nonself asymptotically nonexpansive mapping, then it must be nonself uni-formly Lipschitzian, but the converse does not hold [3].

(iii) If $T$ is a nonself uniformly Lipschitzian mapping or a nonself asymptotically quasi-nonexpansive mapping, then it must be a nonself uniformly quasi-Lipschitzian mapping.

Fixed points iterative technique for (self or nonself) asymptotically nonexpansive mappings in Banach spaces, including Mann type iteration, Ishikawa type iteration, and three-step type iteration, have been studied by many authors (see, e.g., [2-8]). Recently, Khan et al. [9] introduced an iterative scheme (which generalizes Mann iteration, Ishikawa iteration, and three-step iteration) for a finite family of asymptotically quasi-nonexpansive self-mappings $\left\{T_{i}: i \in I\right\}: C \rightarrow C$, where $I=\{1,2, \ldots, k\}$ and $C$ be a convex set. For any initial point $x_{1} \in C$ :

$$
\left\{\begin{array}{l}
x_{n+1}=\left(1-\alpha_{k n}\right) x_{n}+\alpha_{k n} T_{k}^{n} y_{(k-1) n} \\
y_{(k-1) n}=\left(1-\alpha_{(k-1) n}\right) x_{n}+\alpha_{(k-1) n} T_{(k-1)}^{n} y_{(k-2) n} \\
y_{(k-2) n}=\left(1-\alpha_{(k-2) n}\right) x_{n}+\alpha_{(k-2) n} T_{(k-2)}^{n} y_{(k-3) n} \\
\vdots \\
y_{1 n}=\left(1-\alpha_{1 n}\right) x_{n}+\alpha_{1 n} T_{1}^{n} y_{0 n}
\end{array}\right.
$$

where $y_{0 n}=x_{n}$ and $\left\{\alpha_{i n}\right\}$ are real sequences in $[0,1]$ for all $n \geq 1$. They proved the convergence to a common fixed point for a finite family of asymptotically quasi-nonexpansive self-mappings in Banach spaces by using the iterative (1.1).

Inspired and motivated by the above research, we introduce a new iterative process as follows:

Let $C$ be a nonempty convex subset of a real Banach space $X$ and $P: X \rightarrow C$ the nonexpansive retraction of $X$ onto $C$. Assume $T_{i}: C \rightarrow X, i \in I$ be a finite family of nonself uniformly quasi-Lipschitzian mappings. For any $x_{1} \in C$, the sequence $\left\{x_{n}\right\}$ is defined by

$$
\left\{\begin{array}{l}
x_{n+1}=y_{k n}=P\left(\alpha_{k n} x_{n}+\beta_{k n} T_{k}\left(P T_{k}\right)^{n-1} y_{(k-1) n}+\gamma_{k n} u_{k n}\right) \\
y_{(k-1) n}=P\left(\alpha_{(k-1) n} x_{n}+\beta_{(k-1) n} T_{(k-1)}\left(P T_{(k-1)}\right)^{n-1} y_{(k-2) n}+\gamma_{(k-1) n} u_{(k-1) n}\right) \\
y_{(k-2) n}=P\left(\alpha_{(k-2) n} x_{n}+\beta_{(k-2) n} T_{(k-2)}\left(P T_{(k-2)}\right)^{n-1} y_{(k-3) n}+\gamma_{(k-2) n} u_{(k-2) n}\right) \\
\vdots \\
y_{1 n}=P\left(\alpha_{1 n} x_{n}+\beta_{1 n} T_{1}\left(P T_{1}\right)^{n-1} y_{0 n}+\gamma_{1 n} u_{1 n}\right)
\end{array}\right.
$$

where $y_{0 n}=x_{n}$ for all $n \geq 1,\left\{\alpha_{i n}\right\},\left\{\beta_{i n}\right\},\left\{\gamma_{i n}\right\}$ are real sequences in $[0,1]$ with $\alpha_{i n}+$ $\beta_{i n}+\gamma_{i n}=1$ and $\left\{u_{i n}\right\}$ is a bounded sequence in $C$, for $i \in I$.

Remark 1.3. The iterative sequence (1.2) is a natural generalization of the wellknown iteration:

(i) If $\left\{T_{i}: i \in I\right\}$ is asymptotically quasi-nonexpansive self-mappings and $\gamma_{i n}=0$ for $i \in I$ and $n \geq 1$, then the iterative sequence (1.2) reduces to (1.1).

(ii) If $k=2$ and $T_{1}, T_{2}$ are nonself asymptotically nonexpansive mappings, $\gamma_{1 n}=\gamma_{2 n}$ $=0$, then the iterative sequence (1.2) reduces to the Ishikawa type iteration in Wang [8].

(iii) If $k=1$ and $T_{1}$ is a nonself asymptotically nonexpansive mapping, $\gamma_{1 n}=0$, then the iterative sequence (1.2) reduce to the Mann type iteration in Chidume et al. [2]. 
In this article, we are concerned with the convergence to a common fixed point for a finite family of nonself uniformly quasi-Lipschitzian mappings in Banach spaces by using the iterative sequence (1.2). As one will see, our results extend and generalize the corresponding results in [2-10] as follows: (i) the condition $\sum_{n=1}^{\infty}\left(k_{i n}-1\right)<\infty$ is dropped; (ii) the condition $\sum_{n=1}^{\infty} \gamma_{i n}<\infty, i \in I$ is replaced with $\sum_{n=1}^{\infty}\left(\beta_{k n}+\gamma_{k n}\right)<\infty$; (iii) a more general mapping is considered.

We need the following lemma for proving our main results.

Lemma 1.1. ([5]) Let $\left\{a_{n}\right\},\left\{b_{n}\right\}$, and $\left\{c_{n}\right\}$ be sequences of nonnegative real numbers satisfying the following conditions:

$$
a_{n+1} \leq\left(1+b_{n}\right) a_{n}+c_{n}, \forall n \geq 1 .
$$

where $\sum_{n=1}^{\infty} b_{n}<\infty$ and $\sum_{n=1}^{\infty} c_{n}<\infty$, then $\lim _{n \rightarrow \infty} a_{n}$ exists.

\section{Main results}

In this section, we shall prove the strong convergence of the iteration sequence (1.2) to a common fixed point for a finite family of nonself uniformly quasi-Lipschitzian mappings $T_{i}(i \in I)$ in real Banach spaces. We first prove the following lemma.

Lemma 2.1. Let $C$ be a nonempty convex subset of a real normed linear space $X$. Let $\left\{T_{i}: i \in I\right\}: C \rightarrow X$ be a finite family of nonself uniformly quasi-Lipschitzian mappings with $L_{i}>0$, i.e.,

$$
\left\|T_{i}\left(P T_{i}\right)^{n-1} x-p_{i}\right\| \leq L_{i}\left\|x-p_{i}\right\|
$$

for all $x \in C$ and $p_{i} \in \operatorname{Fix}\left(T_{i}\right), i \in I$. Define the sequence $\left\{x_{n}\right\}$ as in (1.2) with $\sum_{n=1}^{\infty}\left(\beta_{k n}+\gamma_{k n}\right)<\infty$. If $F=\bigcap_{i=1}^{k} \operatorname{Fix}\left(T_{i}\right) \neq \emptyset$, then

(i) there exist two constants $M_{0}, M_{1}>0$ such that

$$
\left\|x_{n+1}-p\right\| \leq\left[1+\theta_{n} M_{0}\right]\left\|x_{n}-p\right\|+\theta_{n} M_{1}
$$

where $\theta_{n}=\beta_{k n}+\gamma_{k n}$ for all $n \geq 1, p \in F$.

(ii) there exists a constant $M_{2}>0$, such that

$$
|| x_{n+m}-p\left\|\leq M_{2}|| x_{n}-p\right\|+M_{1} M_{2} \sum_{j=n}^{n+m-1} \theta_{j}
$$

for all $n, m \geq 1, p \in F$.

Proof. (i)We take $p \in F$. Since $\left\{u_{i n}\right\}$ is a bounded sequence in $C$ for all $i \in I$, there exists $M>0$ such that

$$
M=\max _{1 \leq i \leq k}\left\{\left\|u_{\text {in }}-p\right\|\right\} .
$$


Let $L=\max _{1 \leq i \leq k}\left\{L_{i}\right\}>0$. Using (1.2), we have

$$
\begin{aligned}
\left\|y_{1 n}-p\right\| & =\left\|P\left(\alpha_{1 n} x_{n}+\beta_{1 n} T_{1}\left(P T_{1}\right)^{n-1} x_{n}+\gamma_{1 n} u_{1 n}\right)-p\right\| \\
& \leq\left\|\alpha_{1 n} x_{n}+\beta_{1 n} T_{1}\left(P T_{1}\right)^{n-1} x_{n}+\gamma_{1 n} u_{1 n}-\left(\alpha_{1 n}+\beta_{1 n}+\gamma_{1 n}\right) p\right\| \\
& \leq \alpha_{1 n}\left\|x_{n}-p\right\|+\beta_{1 n}\left\|T_{1}\left(P T_{1}\right)^{n-1} x_{n}-p\right\|+\gamma_{1 n}\left\|u_{1 n}-p\right\| \\
& \leq \alpha_{1 n}\left\|x_{n}-p\right\|+\beta_{1 n} L\left\|x_{n}-p\right\|+\gamma_{1 n} M \\
& \leq(1+L)\left\|x_{n}-p\right\|+M .
\end{aligned}
$$

Assume that

$$
\left\|y_{i n}-p\right\| \leq(1+L)^{i}\left\|x_{n}-p\right\|+\sum_{j=0}^{i-1} L^{j} M
$$

holds for some $1 \leq i \leq k-1$. Then

$$
\begin{aligned}
\left\|y_{(i+1) n}-p\right\| & =\left\|P\left(\alpha_{(i+1) n} x_{n}+\beta_{(i+1) n} T_{(i+1)}\left(P T_{(i+1)}\right)^{n-1} \gamma_{i n}+\gamma_{(i+1) n} u_{(i+1) n}\right)-p\right\| \\
& \leq \alpha_{(i+1) n}\left\|x_{n}-p\right\|+\beta_{(i+1) n}\left\|T_{(i+1)}\left(P T_{(i+1)}\right)^{n-1} \gamma_{i n}-p\right\|+\gamma_{(i+1) n}\left\|u_{(i+1) n}-p\right\| \\
& \leq \alpha_{(i+1) n}\left\|x_{n}-p\right\|+\beta_{(i+1) n} L\left\|y_{i n}-p\right\|+\gamma_{(i+1) n}\left\|u_{(i+1) n}-p\right\| \\
& \leq \alpha_{(i+1) n}\left\|x_{n}-p\right\|+\beta_{(i+1) n} L\left[(1+L)^{i}\left\|x_{n}-p\right\|+\sum_{j=0}^{i-1} L^{j} M\right]+\gamma_{(i+1) n}\left\|u_{(i+1) n}-p\right\| \\
& \leq\left[\alpha_{(i+1) n}+\beta_{(i+1) n} L(1+L)^{i}\right]\left\|x_{n}-p\right\|+\beta_{(i+1) n} L \sum_{j=0}^{i-1} L^{j} M+\gamma_{(i+1) n} M \\
& \leq\left[1+L(1+L)^{i}\left\|x_{n}-p\right\|+\sum_{j=1}^{i} L^{j} M+M\right. \\
& \leq(1+L)^{i+1}\left\|x_{n}-p\right\|+\sum_{j=0}^{i} L^{j} M
\end{aligned}
$$

Therefore, by induction, we get for all $i \in I$

$$
\left\|y_{i n}-p\right\| \leq(1+L)^{i}\left\|x_{n}-p\right\|+\sum_{j=0}^{i-1} L^{j} M .
$$

Now, from (1.2), it implies that

$$
\begin{aligned}
\left\|x_{n+1}-p\right\| & =\left\|P\left(\alpha_{k n} x_{n}+\beta_{k n} T_{k}\left(P T_{k}\right)^{n-1} \gamma_{(k-1) n}+\gamma_{k n} u_{k n}\right)-p\right\| \\
& \leq \alpha_{k n}\left\|x_{n}-p\right\|+\beta_{k n} L\left\|\gamma_{(k-1) n}-p\right\|+\gamma_{k n}\left\|u_{k n}-p\right\| \\
& \leq \alpha_{k n}\left\|x_{n}-p\right\|+\beta_{k n} L\left[(1+L)^{k-1}\left\|x_{n}-p\right\|+\sum_{j=0}^{k-2} L^{j} M\right]+\gamma_{k n} M \\
& \leq\left[\alpha_{k n}+\beta_{k n} L(1+L)^{k-1}\right]\left\|x_{n}-p\right\|+\beta_{k n} L \sum_{j=0}^{k-2} L^{j} M+\gamma_{k n} M \\
& \leq\left[1+\theta_{n}(1+L)^{k}\right]\left\|x_{n}-p\right\|+\theta_{n}\left[L \sum_{j=0}^{k-2} L^{j} M+M\right] \\
& \leq\left[1+\theta_{n} M_{0}\right]\left\|x_{n}-p\right\|+\theta_{n} M_{1},
\end{aligned}
$$

where $\theta_{n}=\beta_{k n}+\gamma_{k n}$, and $M_{0}=(1+L)^{k}$, and $M_{1}=\sum_{j=0}^{k-1} L^{j} M$. 
(ii) It is well known that $1+x \leq e^{x}$ for all $x \geq 0$. Estimate (2.1) yields

$$
\begin{aligned}
\left\|x_{n+m}-p\right\| \leq & \left(1+\theta_{n+m-1} M_{0}\right)\left\|x_{n+m-1}-p\right\|+\theta_{n+m-1} M_{1} \\
\leq & e^{\theta_{n+m-1} M_{0}}\left[\left(1+\theta_{n+m-2}\right) M_{0}\left\|x_{n+m-2}-p\right\|+\theta_{n+m-2} M_{1}\right]+\theta_{n+m-1} M_{1} \\
\leq & \quad \ldots e^{\left(\theta_{n+m-1}+\theta_{n+m-2}\right) M_{0}}\left\|x_{n+m-2}-p\right\|+e^{\theta_{n+m-1} M_{0}} M_{1}\left(\theta_{n+m-1}+\theta_{n+m-2}\right) \\
& \quad \ldots \ldots \\
\leq & e^{M_{0} \Sigma_{j=1}^{\infty} \theta_{j}}|| x_{n}-p \|+e^{M_{0} \Sigma_{j=1}^{\infty} \theta_{j}} \cdot M_{1} \cdot \sum_{j=n}^{n+m-1} \theta_{j} \\
\leq & M_{2}\left\|x_{n}-p\right\|+M_{1} M_{2} \sum_{j=n}^{n+m-1} \theta_{j},
\end{aligned}
$$

where $M_{2}=e^{M_{0} \Sigma_{j=1}^{\infty} \theta_{j}}$.

口

Theorem 2.1. Let $C$ be a nonempty closed convex subset of a real Banach space $X$. Let $\left\{T_{i}: i \in I\right\}: C \rightarrow X$ be a finite family of nonself uniformly quasi-Lipschitzian mappings with $L_{i}>0$, i.e.,

$$
\left\|T_{i}\left(P T_{i}\right)^{n-1} x-p_{i}\right\| \leq L_{i}\left\|x-p_{i}\right\|,
$$

for all $x \in C$ and $p_{i} \in F\left(T_{i}\right), i \in I$. Define the sequence $\left\{x_{n}\right\}$ as in (1.2) with $\sum_{n=1}^{\infty}\left(\beta_{k n}+\gamma_{k n}\right)<\infty$. Suppose that $F=\bigcap_{i=1}^{k} \operatorname{Fix}\left(T_{i}\right) \neq \emptyset$ and closed. Then $\left\{x_{n}\right\}$ converges to a common fixed point of $\left\{T_{i}: i \in I\right\}$ if and only if $\liminf _{n \rightarrow \infty} d\left(x_{n}, F\right)=0$, where $d$ $(x, F)=\inf \{\|x-p\|: p \in F\}$.

Proof. The necessity is obvious. Next, we will prove the sufficiency. It follows from Lemma 2.1 that $\left\{x_{n}\right\}$ is bounded. From Lemma 2.1 (i), we have

$$
\begin{aligned}
\left\|y_{1 n}-p\right\| & \leq \alpha_{1 n}\left\|x_{n}-p\right\|+\beta_{1 n} L\left\|x_{n}-p\right\|+\gamma_{1 n}\left\|u_{1 n}-p\right\| \\
& \leq \alpha_{1 n}\left\|x_{n}-p\right\|+\beta_{1 n} L\left\|x_{n}-p\right\|+\gamma_{1 n}\left[\left\|u_{1 n}-x_{n}\right\|+\left\|x_{n}-p\right\|\right] \\
& \leq(1+L)\left\|x_{n}-p\right\|+M^{\prime},
\end{aligned}
$$

where

$$
M^{\prime}=\max _{1 \leq i \leq k}\left\{\left\|u_{\text {in }}-x_{n}\right\|\right\} .
$$

The same to the proof of Lemma 2.1, we get that

$$
\left\|x_{n+1}-p\right\| \leq\left[1+\theta_{n} M_{0}\right]\left\|x_{n}-p\right\|+\theta_{n} M_{1}^{\prime},
$$

where $\theta_{n}=\beta_{k n}+\gamma_{k n}$, and $M_{0}=(1+L)^{k}$, and $M_{1}^{\prime}=\sum_{j=0}^{k-1} L^{j} M^{\prime}$. Taking infimum over all $p$ in $F$, we obtain

$$
d\left(x_{n+1}, F\right) \leq\left(1+\theta_{n} M_{0}\right) d\left(x_{n}, F\right)+\theta_{n} M_{1}^{\prime} .
$$

Note that $M_{1}^{\prime}$ does not depend on $p$.

Since $\sum_{n=1}^{\infty} \theta_{n}=\sum_{n=1}^{\infty}\left(\beta_{k n}+\gamma_{k n}\right)<\infty$ and Lemma 1.1, we get that $\lim _{n} \rightarrow \infty d\left(x_{n}, F\right)$ exists. Furthermore, from $\liminf _{n \rightarrow \infty} d\left(x_{n}, F\right)=0$, we obtain that $\lim _{n \rightarrow \infty} d\left(x_{n}, F\right)=0$. 
We claim that $\left\{x_{n}\right\}$ is a Cauchy sequence. Indeed, for any $\varepsilon>0$, there exists a constant $N_{0}$ such that for all $n \geq N_{0}$, we have

$$
d\left(x_{n}, F\right) \leq \frac{\varepsilon}{4 M_{2}} \text { and } \sum_{i=N_{0}}^{\infty} \theta_{i} \leq \frac{\varepsilon}{4 M_{1} M_{2}} .
$$

In particular, there exists a $p_{1} \in F$ and a constant $N_{1}>N_{0}$, such that

$$
\left\|x_{N_{1}}-p_{1}\right\| \leq \frac{\varepsilon}{4 M_{2}} .
$$

It follows from (2.2) that when $n>N_{1}$, we have

$$
\begin{aligned}
\left\|x_{n+m}-x_{n}\right\| & \leq\left\|x_{n+m}-p_{1}\right\|+\left\|x_{n}-p_{1}\right\| \\
& \leq 2 M_{2}\left\|x_{N_{1}}-p_{1}\right\|+M_{1} M_{2}\left(\sum_{j=N_{1}}^{n+m-1} \theta_{j}+\sum_{j=N_{1}}^{n-1} \theta_{j}\right) \\
& \leq 2 M_{2} \frac{\varepsilon}{4 M_{2}}+M_{1} M_{2}\left(\frac{\varepsilon}{4 M_{1} M_{2}}+\frac{\varepsilon}{4 M_{1} M_{2}}\right)=\varepsilon .
\end{aligned}
$$

Hence, $\left\{x_{n}\right\}$ is a Cauchy sequence in closed convex subset of real Banach spaces. Clearly, $\left\{x_{n}\right\}$ converges to a point of $C$.

Suppose that $\lim _{n \rightarrow \infty} x_{n}=p \in C$. We notice that

$$
\left|d(p, F)-d\left(x_{n}, F\right)\right| \leq\left\|x_{n}-p\right\|,
$$

for all $n \geq 1$. Since $\lim _{n \rightarrow \infty} x_{n}=p$ and $\lim _{n \rightarrow \infty} d\left(x_{n}, F\right)=0$, we conclude that $d(p, F)=0$. Therefore, $p \in F$. $\square$

Corollary 2.1. Let $C$ be a nonempty closed convex subset of a real Banach space $X$. Let $\left\{T_{i}: i \in I\right\}: C \rightarrow X$ be a finite family of nonself uniformly Lipschitzian mappings with $L_{i}>0$. Define the sequence $\left\{x_{n}\right\}$ as in (1.2) with $\sum_{n=1}^{\infty}\left(\beta_{k n}+\gamma_{k n}\right)<\infty$. Suppose that $F=\bigcap_{i=1}^{k} \operatorname{Fix}\left(T_{i}\right) \neq \varnothing$ and closed. Then $\left\{x_{n}\right\}$ converges to a common fixed point of $\left\{T_{i}: i \in I\right\}$ if and only if $\liminf _{n \rightarrow \infty} d\left(x_{n}, F\right)=0$, where $d(x, F)=\inf \{\|x-p\|: p \in F\}$.

Corollary 2.2. Let $C$ be a nonempty closed convex subset of a real Banach space $X$. Let $\left\{T_{i}: i \in I\right\}: C \rightarrow X$ be a finite family of nonself asymptotically nonexpansive mappings (or nonself asymptotically quasi-nonexpansive mappings) with $\left\{k_{i n}\right\}$. Define the sequence $\left\{x_{n}\right\}$ as in (1.2) with $\sum_{n=1}^{\infty}\left(\beta_{k n}+\gamma_{k n}\right)<\infty$. Suppose that $F=\bigcap_{i=1}^{k} \operatorname{Fix}\left(T_{i}\right) \neq \emptyset$ and closed. Then $\left\{x_{n}\right\}$ converges to a common fixed point of $\left\{T_{i}: i \in I\right\}$ if and only if $\liminf _{n \rightarrow \infty} d\left(x_{n}, F\right)=0$, where $d(x, F)=\inf \{\|x-p\|: p \in F\}$.

Proof. Since for all $i \in I,\left\{k_{i n}\right\} \subset[1, \infty)$ and $\lim _{n \rightarrow \infty} k_{i n}=1$, there exists $L_{i}>0$ such that $L_{i}=\sup _{n \geq 1}\left\{k_{i n}\right\}<\infty$. Consequently, $\left\{T_{i}: i \in I\right\}$ is a finite family of nonself uniformly quasi-Lipschitzian mappings with $L_{i}>0$. From Theorem 2.1, we get the desired result. 口

Remark 2.1. (i) When $\left\{T_{i}: i \in I\right\}$ is a finite family of asymptotically nonexpansive self-mappings or asymptotically quasi-nonexpansive self-mappings with $\left\{k_{i n}\right\}$, Corollary 2.2 also holds. 
(ii) In Corollary 2.2, we remove the condition: " $\sum_{n=1}^{\infty}\left(k_{i n}-1\right)<\infty$ ", which is required in many other article (see, e.g., [2,4-9]).

(iii) When considering iterative schemes with errors, many authors need the conditions: " $\sum_{n=1}^{\infty} \gamma_{i n}<\infty, i \in I^{\text {", }}$, see for example [4-6]. But in Corollary 2.2, we only need the condition: " $\sum_{n=1}^{\infty} \theta_{n}<\infty$ ", where $\theta_{n}=\beta_{k n}+\gamma_{k n}$.

Theorem 2.2. Let $C$ be a nonempty closed convex subset of a real Banach space X. Let $\left\{T_{i}: i \in I\right\}: C \rightarrow X$ be a finite family of nonself uniformly quasi-Lipschitzian mappings with $L_{i}>0$. Define the sequence $\left\{x_{n}\right\}$ as in (1.2) with $\sum_{n=1}^{\infty}\left(\beta_{k n}+\gamma_{k n}\right)<\infty$. Suppose that $F=\bigcap_{i=1}^{k} \operatorname{Fix}\left(T_{i}\right) \neq \emptyset$, and closed. If for any given $1 \leq l \leq k$,

(i) $\lim _{n \rightarrow \infty}\left\|x_{n}-T_{1} x_{n}\right\|=0$;

(ii) there exists a constant $\alpha>0$ such that $\left\|x_{n}-T_{l} x_{n}\right\| \geq \alpha d\left(x_{n}, F\right)$ for all $n \geq 1$.

Then $\left\{x_{n}\right\}$ converges to a common fixed point of $\left\{T_{i}: i \in I\right\}$.

Proof. From the conditions (i) and (ii), it implies that $\lim _{n \rightarrow \infty} d\left(x_{n}, F\right)=0$. Therefore, from the proof of Theorem 2.1, $\left\{x_{n}\right\}$ converges to a common fixed point of $\left\{T_{i}: i \in I\right\}$. 口

Remark 2.2. A mapping $T: C \rightarrow X$ is said to be semi-compact, if for any sequence $\left\{x_{n}\right\} \in C$ such that $\lim _{n \rightarrow \infty}\left\|x_{n}-T x_{n}\right\|=0$, there exists a subsequence $\left\{x_{n_{j}}\right\}$ of $\left\{x_{n}\right\}$ such that $\left\{x_{n_{j}}\right\}$ converges strongly to $x^{*} \in C$.

Theorem 2.3. Let $C$ be a nonempty closed convex subset of a real Banach space $X$. Let $\left\{T_{i}: i \in I\right\}: C \rightarrow X$ be a finite family of nonself uniformly quasi-Lipschitzian mappings with $L_{i}>0$. Define the sequence $\left\{x_{n}\right\}$ as in (1.2) with $\sum_{n=1}^{\infty}\left(\beta_{k n}+\gamma_{k n}\right)<\infty$. Suppose that $F=\bigcap_{i=1}^{k} F\left(T_{i}\right) \neq \emptyset$ and closed. If

(i) $\lim _{n \rightarrow \infty}\left\|x_{n}-T_{i} x_{n}\right\|=0$ for all $1 \leq i \leq k$;

(ii) for some $1 \leq l \leq k, T_{l}$ is semi-compact.

Then $\left\{x_{n}\right\}$ converges to a common fixed point of $\left\{T_{i}: i \in I\right\}$.

Proof. Since $T_{l}$ is semi-compact and $\lim _{n \rightarrow \infty}\left\|x_{n}-T_{l} x_{n}\right\|=0$, there exist a subsequence $\left\{x_{n_{j}}\right\} \subset\left\{x_{n}\right\}$ such that $x_{n_{j}} \rightarrow x * \in C$. Consequently, we have

$$
\left\|x^{*}-T_{i} x^{*}\right\|=\lim _{n_{j} \rightarrow \infty}\left\|x_{n_{j}}-T_{i} x_{n_{j}}\right\|=\lim _{n_{j} \rightarrow \infty}\left\|x_{n_{j}}-T_{l} x_{n_{j}}\right\|=0 .
$$

This implies that $x^{*} \in F$. From Theorem 2.1, it follows that

$$
\left\|x_{n+1}-x^{*}\right\| \leq\left[1+\theta_{n} M_{0}\right]\left\|x_{n}-x^{*}\right\|+\theta_{n} M_{1}^{\prime} .
$$

Since $\sum_{n=1}^{\infty} \theta_{n}<\infty$, it implies from Lemma 1.1 that there exist a constant $b \geq 0$ such that

$$
\lim _{n \rightarrow \infty}\left\|x_{n}-x^{*}\right\|=b
$$


From $x_{n_{j}} \rightarrow x^{*}$, we know that $b=0$, i.e., $x_{n} \rightarrow x^{*}$. Thus, $\left\{x_{n}\right\}$ converge to a common fixed point of $\left\{T_{i}: i \in I\right\}$.

口

\section{Acknowledgements}

The authors thank the editor and the referees for constructive and pertinent suggestions. CW was partially supported by the NSF of China (Tianyuan fund for Mathematics, NO.11126290) and Foundation of Nanjing University of Information Science and Technology. JL was partially supported by MOE (Ministry of Education in China) Project of Humanities and Social Sciences (Project No. 12YJC630091).

\section{Author details}

${ }^{1}$ School of Mathematics and Statistics, Nanjing University of Information Science and Technology, Nanjing 210044, People's Republic of China ${ }^{2}$ School of Computer and Information Engineering, Zhejiang Gongshang University, Hangzhou 310018, People's Republic of China ${ }^{3}$ Department of Mathematics, Ningbo University, Zhejiang 315211, People's Republic of China ${ }^{4}$ Department of Mathematics, Tongji University, Shanghai 200092, People's Republic of China

\section{Authors' contributions}

All authors contributed equally and significantly in writing this paper. All authors read and approved the final manuscript.

\section{Competing interests}

The authors declare that they have no competing interests.

Received: 23 August 2011 Accepted: 2 May 2012 Published: 2 May 2012

\section{References}

1. Goebel, K, Kirk, WA: A fixed point theorem for asymptotically nonexpansive mapping. Proc Am Math Soc. 35, 171-174 (1972). doi:10.1090/S0002-9939-1972-0298500-3

2. Chidume, CE, Ofoedu, EU, Zegeye, H: Strong and weak convergence theorems for asymptotically nonexpansive mappings. J Math Anal Appl. 28, 364-374 (2003)

3. Wang, C: Convergence theorems for common fixed points of nonself asymptotically quasi-non-expansive mappings. Fixed Point Theory and Applications 2008, 11 (2008). Article ID 428241, doi:10.1155/2008/428241

4. Fukhar-ud-din, $\mathrm{H}$, Khan, $\mathrm{SH}$ : Convergence of iterates with errors of asymptotically quasi-nonexpansive mappings and applications. J Math Anal Appl. 328, 821-829 (2007). doi:10.1016/j.jmaa.2006.05.068

5. Liu, QH: Iterative sequences for asymptotically quasi-nonexpansive mappings with errors memeber. J Math Anal Appl. 259, 18-24 (2001). doi:10.1006/jmaa.2000.7353

6. Plubtieng, S, Wangkeeree, R, Punpaeng, R: On the convergence of modified Noor iterations with errors for asymptotically nonexpansive mappings. J Math Anal Appl. 322, 1018-1029 (2006). doi:10.1016/j.jmaa.2005.09.078

7. $\mathrm{Xu}, \mathrm{BL}$, Noor, MA: Fixed point iterations for asymptotically nonexpansive mappings in Banach spaces. J Math Anal Appl. 267, 444-453 (2002). doi:10.1006/jmaa.2001.7649

8. Wang, L: Strong and weak convergence theorems for common fixed points of nonself asymptotically nonexpansive mappings. J Math Anal Appl. 323, 550-557 (2006). doi:10.1016/j.jmaa.2005.10.062

9. Khan, AR, Domlo, AA, Fukhar-ud-din, H: Common fixed points Noor iteration for a finite fanily of asymptoticlly quasinonexpansive mappings in Banach spaces. J Math Anal Appl. 34, 1-11 (2008)

10. Dehghan, $\mathrm{H}$, Rooin, J: A new three-step mean value iterations with errors for asymptotically nonexpansive mappings in Banach spaces. Thai J Math. 9, 631-645 (2011)

doi:10.1186/1687-1812-2012-72

Cite this article as: Wang et al:: New iterative schemes for a finite family of nonself uniformly quasi-Lipschitzian mappings in Banach spaces. Fixed Point Theory and Applications 2012 2012:72.

\section{Submit your manuscript to a SpringerOpen ${ }^{\circ}$ journal and benefit from:}

- Convenient online submission

Rigorous peer review

- Immediate publication on acceptance

- Open access: articles freely available online

- High visibility within the field

- Retaining the copyright to your article

Submit your next manuscript at $\mathbf{s p r i n g e r o p e n . c o m ~}$ 